\title{
UNIFORMLY EXPONENTIAL DICHOTOMY FOR STRONGLY CONTINUOUS QUASI GROUPS
}

\author{
Sutrima Sutrima*, MARdiYAna MARdiYANA AND RIRIN SETIYOWATI
}

Abstract. A strongly continuous quasi group ( $C_{0}$-quasi group) is established as an extension of a $C_{0}$-quasi semigroup on a Banach space. The fundamental properties of the $C_{0}$-quasi groups are derived from the properties of $C_{0}$-quasi semigroups. It is identified a sufficient condition for an infinitesimal generator of a $C_{0}$-quasi group. The infinitesimal generator of a $C_{0}$-quasi group generates a non-autonomous the abstract Cauchy problem that is well-posed. Uniformly exponential stability of the $C_{0}$-quasi groups and the $C_{0}$-quasi semigroups on a Banach space $X$ can be identified by the associated evolution semigroups on the spaces $L_{p}(\mathbb{R}, X)$ and $L_{p}\left(\mathbb{R}^{+}, X\right)$, $1 \leqslant p<\infty$, respectively. The sufficient and necessary conditions, called Dichotomy Theorem, for the uniformly exponential dichotomy of the $C_{0}$-quasi groups and the $C_{0}$-quasi semigroups are characterized by the associated evolution semigroups. The hyperbolicity of the evolution semigroups is used in the characterization. Dichotomy Theorem can also be identified by a Green's function induced by the associated evolution semigroup. Moreover, the infinitesimal generator of the associated evolution semigroup becomes the main subject in establishment of the sufficiency and necessity for the uniformly exponential stability of the $C_{0}$-quasi semigroups.

Mathematics subject classification (2010): 34D09, 47D03.

Keywords and phrases: $C_{0}$-quasi group, evolution semigroup, uniformly exponentially stable, Dichotomy Theorem, Green's function.

\section{REFERENCES}

[1] H. Bart, I. Gohberg And M. A. KAASHOEK, Wiener-Hopf factorization, inverse Fourier transform and exponentially dichotomous operators, J. Funct. Anal., 68: 1-42, 1986.

[2] C. BUşE, On nonuniform exponential stability of evolutionary process, Rend. Sem. Mat. Univ. Poi. Torino, 52 (4): 396-406, 1994.

[3] C. Buşe, M. Megan, M. Praje And P. Preda, The strong variant of a Barbashin's Theorem on stability of solution for non-autonomous differential equations in Banach spaces, Integr. Eqns. Oper. Th., 59 (4): 491-500, 2007.

[4] C. Chicone And Y. LATUShKin, Evolution semigroups in dyamical systems and differential equations, Americans Mathematical Society, USA, 1999.

[5] V. CuC, Generalization of a theorem of Datko and Pazy for $C_{0}$-quasi semigroups, Demonstr. Math., 34 (3): 577-586, 2001.

[6] R. Datko, Extending a theorem of A. M. Lyapunov to Hilbert space, J. Math. Anal. Appl., 32: 610$616,1970$.

[7] K. J. Engel And R. NAGEL, One-parameter semigroups for linear evolution equations, SpringerVerlag, New York, 2000.

[8] D. E. EvAns, Time dependent perturbations and scattering of strongly continuous groups on Banach spaces, Math. Ann., 221: 275-290, 1976.

[9] J. S. Howland, Stationary Scattering Theory for Time-dependent Hamiltonians, Math. Ann., 207: 315-335, 1974.

[10] P. E. T. JORGENSEN, Spectral theory for infinitesimal generators of one-parameter groups of isometries: the min-max principle and compact perturbations, J. Math. Anal. Appl., 90: 343-370, 1982.

[11] C. S. KubRusly, Spectral theory of operators on Hilbert spaces, Birkhäuser, New York, 2012. 
[12] Y. Latushin And S. Montgomery-Smith, Lyapunov theorems for Banach spaces, Bull. Amer. Math. Soc., 31 (1): 44-49, 1994.

[13] Y. LATUShKin AND S. Montgomery-Smith, Evolutionary semigroups and Lyapunov theorems in Banach spaces, J. Funct. Anal., 127: 173-197, 1995.

[14] Y. LATUShKin AND T. RANDOLPh, Dichotomy of differential equations on Banach spaces and an algebra of weighted composition operators, Integr. Eqns. Oper. Th., 23: 472-500, 1995.

[15] R. DE LAUbENFEL, Storngly continuous groups, similarity and numerical range on a a Hilbert space, Taiwan. J. Math., 1: 127-133, 1997.

[16] H. LeIVA AND D. BARCenas, Quasi-semigroups, evolution equation and controllability, Notas de Matematicas, 109: 1-29, 1991.

[17] N. LEVAN AND C. S. KUBRUSLY, Exponential dichotomy and strongly stable vectors of Hilbert space contraction semigroups, Mat. Vesnik, 65 (2): 166-177, 2013.

[18] K. LIU, A charcterizaton of strongly continuous of linear operators on a Hilbert space, Bull. London Math. Soc., 32: 54-62, 2000.

[19] M. Megan And V. CuC, On exponential stability of $C_{0}$-quasi semigroups in Banach spaces, Le Matematiche, LIV (1999): 229-241, 1999.

[20] M. Megan, B. Sasu AND A. L. SASU, On non-uniform exponential dichotomy of evolution operators in Banach spaces, Integr. Eqns. Oper. Th., 44: 71-78, 2002.

[21] N. V. Minh, F. RABiger ANd R. Schnaubelt, Exponential stability, exponential expansiveness, and exponential dichotomy of evolution equations on the half-line, Integr. Eqns. Oper. Th., 32: 332353, 1998.

[22] R. NAGEL, Semigroup methods for non-autonomous Cauchy problems, in Evolution Equations, Lect. Notes Pure Appl. Math., 168: 301-316, 1995.

[23] H. NeIDHARDT, Linear non-autonomous Cauchy problems and evolution semigroups, Adv. Differential Equations, 14 (3-4): 289-340, 2009.

[24] A. G. NiCKEL, On evolution semigroups and wellposedness of non-autonomous Cauchy problems, Dissertation, The Mathematical Faculty of the Eberhard-Karls-University Tubingen, Berlin, 1996.

[25] A. G. NICKEL, Evolution semigroups and product formulas for non-autonomous Cauchy problems, Math. Nach., 212: 101-116, 2000.

[26] A. PAZY, On the applicability of Lyapunov's Theorem in Hilbert space, SIAM J. Math. Anal., 3 (2): 291-294, 1972.

[27] A. PAZY, Semigroups of Linear Operators and Applications to Partial Differential Equations, Springer, New York, 1983.

[28] C. Pötzsche, A note on the dichotomy spectrum, J. Difference Equ. Appl., 15 (10): 1021-1025, 2009.

[29] P. Preda And M. Megan, Exponential dichotomy of strongly continuous semigroups, Bull. Austral. Math. Soc., 30: 435-448, 1984.

[30] P. Preda And M. Megan, Exponential dichotomy of evolutionary processes in Banach spaces, Czechoslovak Math. J., 35 (110): 312-323, 1985.

[31] R. RAU, Hyperbolic evolutionary semigroups on vector-valued function spaces, Semigroup Forum, 48: 107-118, 1994.

[32] J. SChmid, Well-posedness of Non-Autonomous Linear Evolution Equations for Generators whose Commutators are Scalar, J. Evol. Equ., 16: 21-50, 2016.

[33] J. SCHMid AND M. GRIESEMER, Well-posedness of Non-Autonomous Linear Evolution Equations in Uniformly Convex Spaces, Math. Nachr., 290: 435-441, 2017.

[34] R. Schnaubelt, Sufficient conditions for exponential stability and dichotomy of evolution equations, Forum Math., 11: 543-566, 1999.

[35] S. Sutrima, C. R. Indrati, L. ARyati And Mardiyana, The fundamental properties of quasi semigroups, J. Phys. Conf., Article ID 855(2017)012052: 1-9, 2017.

[36] S. Sutrima, C. R. Indrati AND L. ARYATI, Stability of $C_{0}$-quasi semigroups in Banach spaces, J. Phys. Conf., Article ID 943(2017)012021: 1-14, 2017.

[37] S. Sutrima, C. R. IndRati AND L. ARYati, Controllability and observability of non-autonomous Riesz-spectral systems, Abstr. Appl. Anal., Articel ID 4210135: 1-10, 2018.

[38] S. Sutrima, C. R. Indrati And L. Aryati, Exact null controllability, stabilizability, and detectability of linear non-autonomous control systems: A quasi semigroup approach, Abstr. Appl. Anal., Article ID 3791609: 1-12, 2018. 
[39] S. Sutrima, C. R. Indrati AND L. Aryati, Contraction quasi semigroups and their applications in decomposing Hilbert spaces, Azerb. J. Math., 10 (1): 57-74, 2020.

[40] A. Tajmouati, M. Karmouni And Y. Zahouan, Quasi-Fredholm and Saphar spectra for $C_{0}$ quasi-semigroups, Adv. Oper. Theory, 5 (4): 1325-1339, 2020. 